\title{
Effect of Al deoxidizing for Spring steel during LF Process
}

\author{
Wei $\operatorname{Lin}^{1, a}$ \\ ${ }_{1}^{1}$ NO.1, Saidi Road, Jinyu Avenue, Yubei District 401122, Chongqing, China \\ a51891403@qq.com
}

Keywords: Spring steel, Al deoxidizing, Non-metallic inclusions.

Abstract. Effect of Al deoxidizing for Spring steel during LF Process is investigated in this paper. The deoxidation system includes aluminum precipitation deoxidation when tapping, then strengthening diffuse deoxidation with adding adequate aluminum to the surface of the LF slag. It is found that the inclusions in steel have been effectively controlled, and the ultimate inclusions in the ingot is mainly $\mathrm{CaO}-\mathrm{MgO}-\mathrm{Al}_{2} \mathrm{O}_{3}-\mathrm{CaS}$ composite inclusion, the size of which is mostly less than $5 \mu \mathrm{m}$. $\mathrm{Al}$ deoxidizing is helpful to improve the quality of spring steel.

\section{Introduction}

The cleanness of the spring steel has a very important influence on the service life of the spring[1]. So, it has a remarkable effect on improving the fatigue resistance ability that reduces the oxygen content and the non-metallic inclusions, and improves the shape and distribution of the inclusions, especially, the big grain, high melting point brittle inclusions such as alumina and aluminate, and pointed titanium nitride inclusions which is the main causation that causes the breakage of the spring[2]. After Al deoxidizing during LF refining treatment, most of non-metallic inclusions in liquid steel are transformed into tiny globular inclusions, which is helpful to improve the quality of steel[3].

\section{Al Deoxidation System in LF Refining process}

The operation process discussed in this paper is the addition of refining slag, submerged arc slag and fluorite in LF refining process, which ensures the formation of high reductive slag in 10 minutes of power supply, adding aluminum particles into the slag and the strong diffusion deoxidization to create a good low oxidation condition. The steel water is sent to VD after LF refining to be vacuum treated. Figure 1 shows the variation of T.O in three heats of molten steel tested with Al deoxidation system.

After precipitation and deoxidation, the dissolved oxygen in the steel is very low. The reduction of total oxygen mainly lies in controlling the oxidation property of slag and preventing slag from transferring oxygen to molten steel. At the same time, it is necessary to use various methods to promote inclusion floating. Due to the addition of sufficient aluminum for diffusion and deoxidation during $\mathrm{LF}$ refining, the resulting $\mathrm{Al}_{2} \mathrm{O}_{3}$ inclusions are continuously floated and the molten steel T.O decreases to about 10ppm.

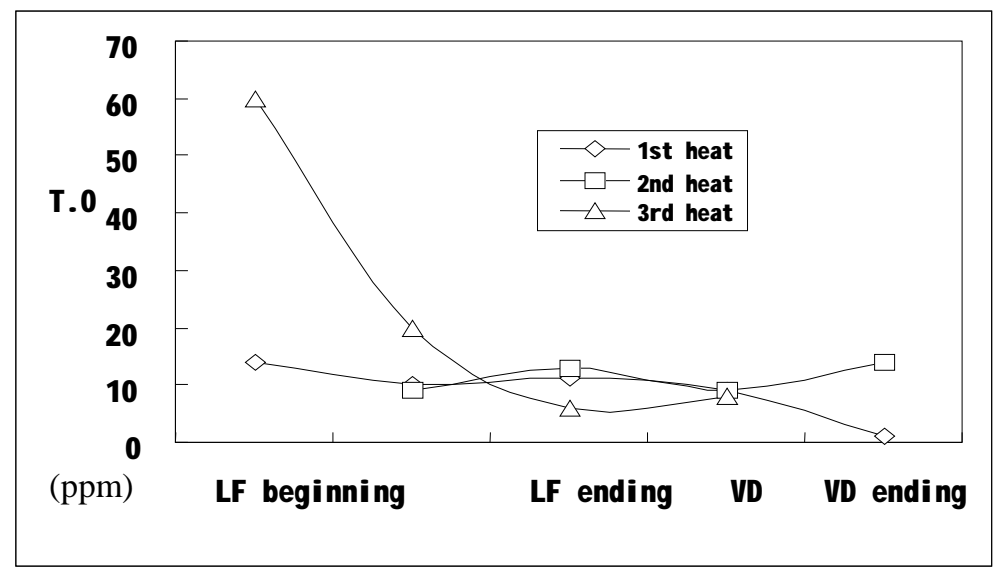

Fig.1. Variation of T.O in refining process 


\section{The Analysis of Non-metallic Inclusions during LF Treatment}

After adding enough aluminum to deoxidize molten steel at the initial refining stage, the dissolved oxygen in liquid steel will be reduced to a very low level in $2 \sim 3 \mathrm{~min}$ due to the very strong deoxidizing ability of aluminum. Fig. 2 shows the dominant regions of different deoxidized products of alcansianum at $1873 \mathrm{k}$. It can be seen that the main deoxidation products in aluminum deoxidized steel are $\mathrm{Al}_{2} \mathrm{O}_{3}$.

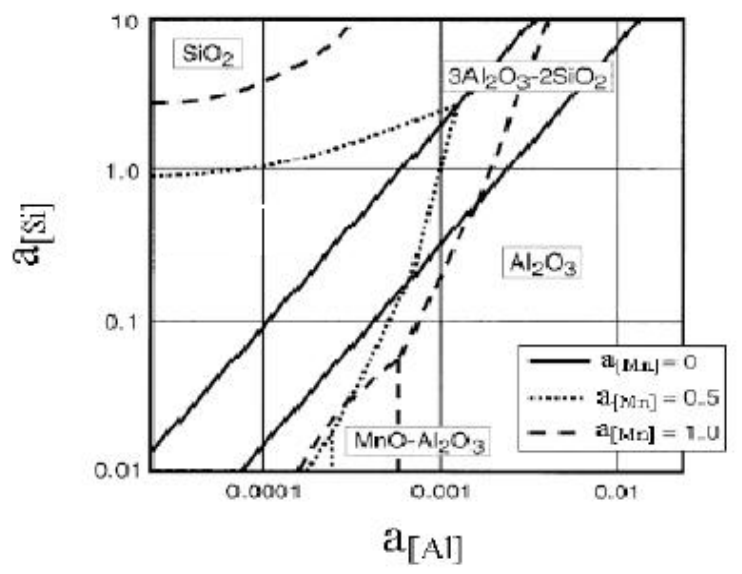

Fig.2. Dominant region map of Fe-Al-Si-Mn-O system

The steel samples is taken at the early stage(the beginning of LF treatment), the middle stage (15 minutes after charging deoxidizer) and the end of LF refining process. Steel samples were polished and the chemical composition and profile of inclusions in steel samples were analyzed by SEM-EDS.The pictures of non-metallic inclusions in steel samples in the early stage of LF refining are shown in figure 3 below.

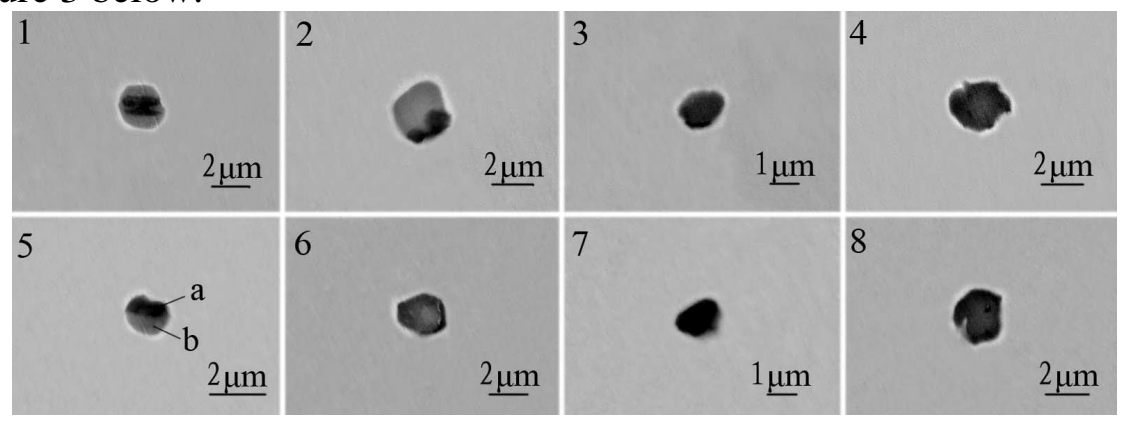

Fig.3. Non-metallic inclusions of steel samples at the early stage of LF treatment

It can be analyzed by SEM-EDS that the non-metallic inclusions in the early stage are mainly $\mathrm{Al}_{2} \mathrm{O}_{3}$ and $\mathrm{MnS}-\mathrm{MnO}-\mathrm{Al}_{2} \mathrm{O}_{3}$ composite inclusions, and the size of the inclusions is small, most of the inclusions are below $5 \mu \mathrm{m}$ in size, and the shape of the inclusions is massive and spherical. No cluster $\mathrm{Al}_{2} \mathrm{O}_{3}$ inclusions were observed.

The fig. 4 shows the non-metallic inclusions of steel samples which were taken at the middle stage of the $\mathrm{LF}$ refining process when adopting $\mathrm{Al}$ deoxidation system. It is shown that the inclusions are $\mathrm{MgO}-\mathrm{Al}_{2} \mathrm{O}_{3}-\mathrm{CaO}-\mathrm{CaS}$ inclusions, in which the $\mathrm{CaS}$ content of desulfurization products is very high , and there is a small amount of angular $\mathrm{TiN}$ and $\mathrm{TiO}_{2}$ inclusions which are wrapped outside the $\mathrm{MgO}-\mathrm{Al}_{2} \mathrm{O}_{3}-\mathrm{CaO}-\mathrm{CaS}$ inclusions. With the refining process, the content of $\mathrm{Al}_{2} \mathrm{O}_{3}$ in inclusions decreases gradually, and the large size inclusions float up and down. The size of inclusions is below 5 $\mu \mathrm{m}$. 


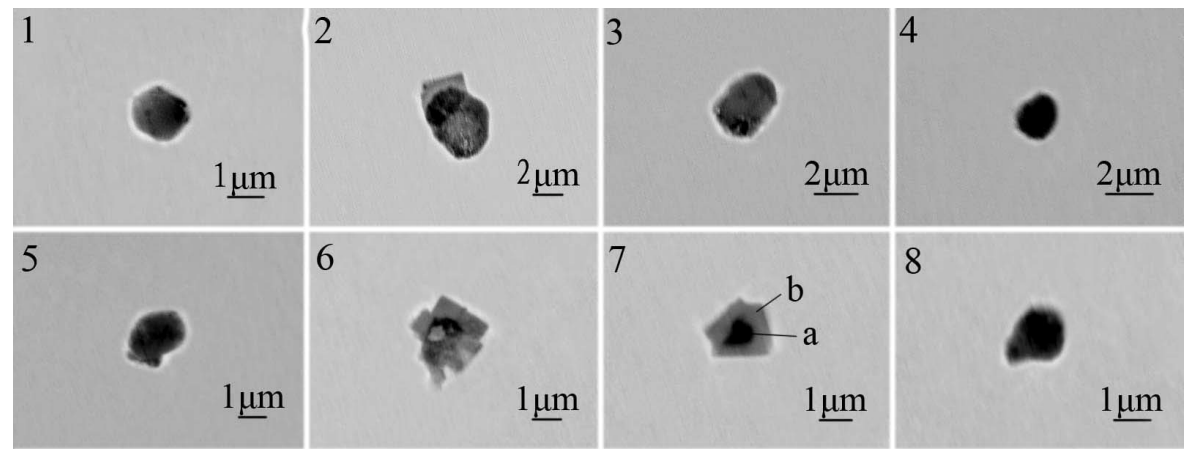

Fig.4. Non-metallic inclusions of steel samples at the middle stage of LF treatment

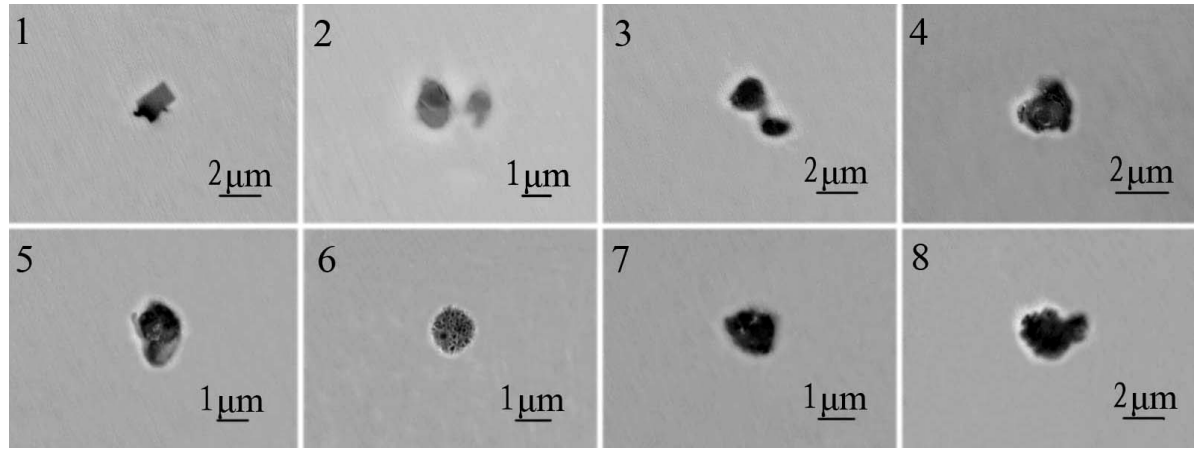

Fig.5. Non-metallic inclusions of steel samples at the end of LF treatment

The fig. 5 shows pictures of inclusions observed in molten steel samples at the end of LF refining using Al deoxidation system. By SEM-EDS analysis, it was found that most of the inclusions were $\mathrm{CaO}-\mathrm{CaS}$ inclusions, and sometimes a small amount of $\mathrm{Al}_{2} \mathrm{O}_{3}$ or $\mathrm{MgO}$ was found. There are also a small amount of angular TiN and $\mathrm{TiO}_{2}$ inclusions. The content of $\mathrm{Al}_{2} \mathrm{O}_{3}$ in inclusions is less than that after the formation of white slag in the middle period. The inclusion size is not uniform, most of which are below $5 \mu \mathrm{m}$. The shapes of inclusions are mostly circular or elliptical.

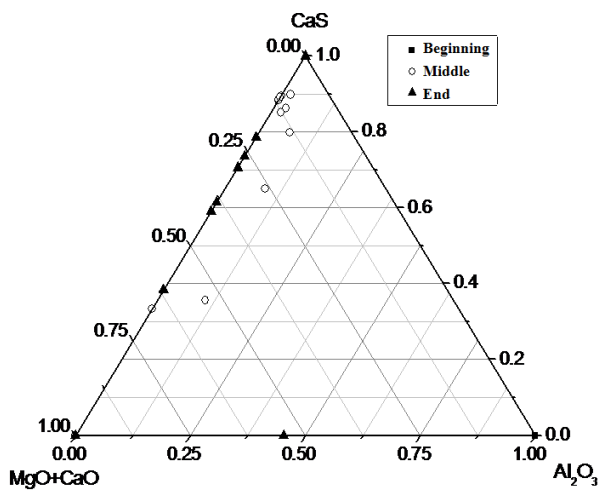

Fig.6. Inclusion ternary diagram of LF refining process

The fig. 6 shows the variation of inclusions in the process of LF refining. Adding appropriate amount of aluminum particles improves the slag, and the refining slag with high alkalinity and low oxidation is quickly formed which has very strong desulphurization ability. By the stirring effect of argon blowing in the liquid steel, the following reactions proceeded smoothly:

$3[\mathrm{~S}]+3(\mathrm{CaO})+2[\mathrm{Al}]=\left(\mathrm{Al}_{2} \mathrm{O}_{3}\right)+3(\mathrm{CaS})$

The reaction product cas was precipitated on other inclusions in steel, forming $\mathrm{CaO}(\mathrm{MgO})$ $\mathrm{Al}_{2} \mathrm{O}_{3}-\mathrm{CaS}-\mathrm{SiO}_{2}$ complex inclusions. Due to the addition of sufficient amount of strong deoxidizer aluminum, a large number of clusters of $\mathrm{Al}_{2} \mathrm{O}_{3}$ can be formed, which is easy to be removed by floatation. 


\section{Conclusions}

By analysing the effect of $\mathrm{Al}$ deoxidizing during LF refining process, conclusions are drawn as below.

Adding sufficient amount of aluminum strong deoxidizer and slagging agent, the high alkalinity and low oxidizing slag can be formed as early as possible in the LF refining process. This refining slag has high desulfurization ability.

The main non-metallic inclusions observed at the initial refining stage of LF treatment were $\mathrm{Al}_{2} \mathrm{O}_{3}$ and $\mathrm{MnS}-\mathrm{MnO}-\mathrm{Al}_{2} \mathrm{O}_{3}$ composite inclusions, and the $\mathrm{Al}_{2} \mathrm{O}_{3}$ content in the inclusions decreased gradually in the middle stage of refining. The inclusions changed to the $\mathrm{CaO}-\mathrm{Al}_{2} \mathrm{O}_{3}$. Moreover, the modified calcium aluminate was located in the low melting point region of $\mathrm{C}_{3} \mathrm{~A}, \mathrm{C}_{12} \mathrm{~A}_{7}$ and $\mathrm{CA}$. This kind of inclusions were easy to be removed in liquid steel.

By adopting $\mathrm{Al}$ deoxidation system, the inclusions in steel have been effectively controlled. At the end of LF refining process, most of non-metallic inclusions have been transformed into tiny globular $\mathrm{CaO}-\mathrm{MgO}-\mathrm{Al}_{2} \mathrm{O}_{3}-\mathrm{CaS}$ composite inclusions which are helpful for the improvement of the quality of spring steel.

\section{References}

[1] Zhian Yang and Zhirui Wang, Effect of prestrain on cyclic reap behavior of high strength spring steel. Materials Science and Engineering(A210,1996), PP.83

[2] H.V.Atkinson and G.Shi, Characterization of inclusions in clean steels:a review including the statistics of extremes methods[J]. Progress in Materials Science(2003,(48)), PP.457

[3] Duckworth W E. and Ineson E., Clean steel. 77(Iron Steel Inst. 1963), PP.87 